DEMOGRAPHIC RESEARCH

VOLUME 38, ARTICLE 54, PAGES 1635-1662

PUBLISHED 16 MAY 2018

http://www.demographic-research.org/Volumes/Vol38/54/

DOI: 10.4054/DemRes.2018.38.54

Research Article

Non-zero trajectories for long-run net migration assumptions in global population projection models

Guy J. Abel

(C) 2018 Guy J. Abel.

This open-access work is published under the terms of the Creative Commons Attribution 3.0 Germany (CC BY 3.0 DE), which permits use, reproduction, and distribution in any medium, provided the original author(s) and source are given credit.

See https://creativecommons.org/licenses/by/3.0/de/legalcode. 


\section{Contents}

1 Introduction 1636

$2 \quad$ Net migration data 1637

$3 \quad$ Future migration scenarios 1639

3.1 The short and medium run 1639

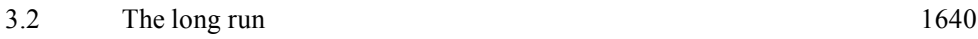

$4 \quad$ Alternative long-run migration scenarios 1641

4.1 Persistence scenario (SSP2) 1643

4.2 Other scenarios (SSP1, SSP3, SSP4, and SSP5) 1644

4.3 Net migration trajectories 1645

$5 \quad$ Population projection under alternative migration scenarios $\quad 1648$

6 Discussion 1651

$7 \quad$ Acknowledgments 1653

$\begin{array}{ll}\text { References } & 1654\end{array}$

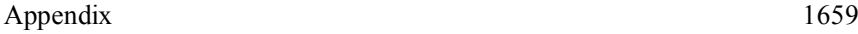




\title{
Non-zero trajectories for long-run net migration assumptions in global population projection models
}

\author{
Guy J. Abel ${ }^{1}$
}

\begin{abstract}
BACKGROUND

Little attention is given to the role of migration in global population projection models. Most demographers set future levels of net migration on trajectories towards zero in all countries, nullifying the impact of migration on long-run projected populations. Yet as fertility and mortality rates fall, the role of migration on future population change is becoming more pronounced.
\end{abstract}

\section{OBJECTIVES}

In this paper we develop future long-run migration scenarios to provide a range of possible outcomes.

\section{METHODS}

Our alternative migration scenarios are linked to the Shared Socioeconomic Pathways (SSP), widely used in research on global environmental change. These are utilized as inputs for a global cohort component projection model to obtain population totals up until 2100 for all countries.

\section{CONTRIBUTION}

The results illustrate the important role of migration assumptions in long-run projections, especially in post-demographic-transition countries. Further, they provide plausible alternatives to projections based on the commonly used, but poorly justified, convergence towards a zero net migration assumption.

\footnotetext{
${ }^{1}$ Asian Demographic Research Institute, School of Sociology and Political Science, Shanghai University, China and Wittgenstein Centre (IIASA, VID/ÖAW, WU), International Institute for Applied Systems Analysis, Austria. Email: guy.abel@shu.edu.cn.
} 


\section{Introduction}

Long-run demographic projections are useful for assessing hypothetical future population trends and their determinants. They help identify realistic development targets and provide a base for other projections essential for social and economic planning in fields such as climate, energy, and social security. International migration is commonly considered as a major source of uncertainty in long-run global population projections (National Research Council 2000) and an important driver of demographic growth in many developed countries, often accounting for over half of the population change (Lee 2011). The rise in the influence of migration is likely to spread to more countries as fertility and mortality rates continue to fall in the developing world.

The accurate prediction of future international migration is one of the most difficult challenges in long-run population projections. Data on past trends of international migration flows, used to inform future assumptions, is often limited in availability and comparability. Unlike other components of demographic change, there is no overriding transition theory or agreed causal mechanisms to explain patterns of international migration (Massey et al. 1993). Further, explanatory variables for social, economic, and political factors that might aid the forecasting of future migration may be as difficult to forecast as migration levels themselves (Bijak and Wiśniowski 2010).

Given the difficulties facing the prediction of future migration, methods based on scenarios without any probabilistic statement attached are commonly used in population projections produced by national statistics institutes and international organizations (Bijak 2012; Howe and Jackson 2004). Global population projection models, the focus of this paper, use similar scenario assumptions for the long-run future levels of international migration. Migration assumptions in these models tend to follow the lead of the United Nations (UN), who since their 2010 version of the World Population Prospects (WPP) have produced projections up until 2100 with a medium scenario where net migration levels are assumed to follow a trajectory converging towards zero in all countries from 2050 onwards.

In this paper we develop multiple migration scenarios and then incorporate them into global population projections. Our scenarios are constructed to match long-run migration patterns described in the Shared Socioeconomic Pathways (SSP) (O'Neill et al. 2014), which are widely used in research on global environmental change. A range of migration assumptions has a number of appealing properties. First, the use of multiple scenarios helps users understand what aspects of populations and structures are sensitive to alternative migration patterns and which are not affected (Lutz 1991). Second, multiple scenarios that reflect policy-relevant future narratives directly interpret possible outcomes, unlike a zero migration scenario (Booth 2006). Third, in situations where statistical forecasts of demographic variables might have 
overwhelming levels of uncertainty, scenarios enable a better comprehension of the impact of potential changes on population projections (Bijak 2011).

The first of these properties is of particular relevance in the context of global population projection models where the standard procedure of setting a future net migration on a trajectory towards zero in all countries is almost universally maintained. This assumption reduces the role of migration as a driver of population change, despite its prominent role in the demography of many countries. As Chamie (2016) discusses, ignoring the likelihood of large-scale international migration flows in years ahead may be politically expedient, especially for those advocating tightened borders and restrictions for migrant admissions. However, doing so is shortsighted, misguided, and ill-advised, and will undermine policy development, responsible planning, and program readiness for the international migration exodus of the $21^{\text {st }}$ century.

The SSP projections of net migration developed in this paper and the resulting projected populations are purely deterministic with no probabilistic statement attached. This follows the practice of other SSP projection exercises for other socioeconomic measures. Probabilistic methods to forecast net migration for all countries have recently been developed by Azose and Raftery (2015) and Azose, Ševčíková, and Raftery (2016). These are not utilized in this paper, not only because the output is nondeterministic but also because the inclusion of future migration levels to match policy-relevant futures would involve a nontrivial elicitation of expert-based prior distributions for future migration levels, and an even more complex alteration to their model to incorporate the prior information.

This article proceeds with an overview of past net migration estimates provided by the UN, followed by a review of the migration assumptions of the main producers of world population projections, such as the UN, the US Census Bureau, and demographers at the Wittgenstein Centre (WiC). In Section 4 a set of alternative migration scenarios for all countries is proposed and discussed in the context of each SSP. In Section 5 these alternative migration assumptions are used in a global population projection model with the same future fertility and mortality rates. These are compared with projections based on the UN assumption of a convergence towards zero net migration in all countries. The results are discussed in the final section and are related to potential future research in the area.

\section{Net migration data}

Global population projection requires both base data in the launch period and assumptions regarding the future trajectory of each demographic component. Both the UN Population Division and the US Census Bureau estimate net migration by age and 
sex over five-year periods for all countries. This section focuses on the UN estimates, for three reasons. First, past versions of the UN net migration estimates are available, allowing a study of past revisions. Second, the estimation methods used by the US Census Bureau are similar to those of the UN (for an in-depth comparison, see Buettner and Muenz 2016). Third, demographers at $\mathrm{WiC}$ use estimates of bilateral migration flows from a global demographic accounting framework that sum to the UN net migration estimates in each country (summing all the immigration flows by origin and then subtracting all the emigration flows by destination).

Official statistics on net migration that match the five-year interval commonly used as a timing interval when developing global population projections are in very short supply. There are a number of reasons for the lack of data. First, no country can collect statistics on the number of net migrants as they are a nonexistent population (Rogers 1990). Second, most countries do not collect the data on the number of immigrants and emigrants that might enable a net migration estimate to be produced. Third, in countries that do collect data on the number of immigrants and emigrants the data often lacks adequate measurements of volume, direction, and completeness (Kelly 1987; Kupiszewska and Nowok 2008; Willekens 1994). Finally, where an adequate data collection system exists, migration statistics are not commonly published over five-year time intervals or aligned to the same points of time as the projection launch period.

For these reasons, net migration values produced by the UN are estimated based on a combination of intercensal net residuals derived from population accounting and official migration statistics, where they exist. Estimates might represent not only net migration counts but also accumulated statistical errors from population, fertility, and mortality measures. Further statistical errors might result from adjustments carried out to ensure that the total global net migration is zero in each five-year period.

The UN does not provide disaggregation of net migration values by age and sex, as required in cohort component projection models,. However, such data can be indirectly estimated given age-specific population, birth, and death data. ${ }^{2} \mathrm{UN}$ documentation notes that their disaggregation of estimated net migration is dependent on the participation of men and women in different types of flows for any given country (i.e., labor migration, family reunification, etc.). Where no existing age disaggregation exists,

\footnotetext{
${ }^{2}$ For the 2008, 2010, and 2012 WPP versions, net migration data by age and sex for all countries are available in R packages (Ševčíková et al. 2013; Ševčíková and Gerland 2013). Within the help files of the net migration data a disclaimer notes that the data is for illustrative purposes only and incorporates statistical adjustment errors. For the 2008 and 2010 versions, past estimates go back to 1990-1995; for the 2012 version, estimates go back to 1950-1955. Net migration data by age and sex is not available in the WPP2015 and WPP2017 R packages (Ševčíková 2017; United Nations Department of Economic and Social Affairs Population Division 2015 b) but an R function to indirectly derive these values via demographic accounting is provided.
} 
model age schedules are used to distribute the overall net number of male and female migrants by age group according to the dominant type of migration flow assumed; for example, labor migration or family migration (United Nations Department of Economic and Social Affairs Population Division 2014: 37). For full details on the methodology used to estimate past net migration, see the UN methodology literature (for example, United Nations Department of Economic and Social Affairs Population Division 2017).

\section{Future migration scenarios}

The development of future migration assumptions can be separated into two components. The first involves adjustments to alter levels of migration in the immediate future. These are typically carried out on a country-by-country basis using expert opinion. In the second component, migration levels are set according to assumptions about the global migration system. In this section we briefly discuss both of these components in reference to the migration assumptions used in global population projections published by the UN, the US Census Bureau, and researchers at the Wittgenstein Centre. A more comprehensive discussion of comparisons between the future migration scenarios used by each of these groups can be found in Buettner and Muenz (2016).

\subsection{The short and medium run}

In countries where migration plays an important role, demographers often adjust migration levels to assumptions in the immediate future in response to the social, political, and economic climate. In both the past and present versions of the WPP, experts at the UN adjust the size and direction of the changes in net migration during the initial projection periods based on available migration statistics, national governments' views on international migration, estimates of undocumented migrants, and data on refugee movement (United Nations Department of Economic and Social Affairs Population Division 2014: 37). In some countries these changes can be immediate, with sudden shifts from past patterns to levels in the next projection periods, which are then kept constant up until 2050. For other countries it is assumed that the change in net migration can be a slower process, drifting over a couple of decades towards a level which is then held in the medium-to-long term.

Both the US Census Bureau and the WiC use expert assumptions to make modifications to future migration levels in their projections, using similar arguments to the UN. As Coleman (2004) noted, when making population projection assumptions for 
net receiving countries, expert-driven levels for future migration invariably posit a rapid decline in net immigration, partly so as not to contradict national government policy aimed at minimizing inflows and partly due to the difficulty of working out what will happen in the future.

\subsection{The long run}

Throughout recent WPP versions the UN have used two migration scenarios in their projection models: a medium migration scenario and a zero migration scenario. The zero migration scenario is typically used only once, to enable a clearer understanding of natural population change. ${ }^{3}$

In recent versions of the WPP, net migration assumptions have been set until 2100, whereafter 2050 levels in all countries are assumed to converge at a linear rate towards zero. In both WPP2010 and WPP2012 net migration is assumed to converge to zero by 2095-2100 in all countries. In WPP2015 and WPP2017 net migration converges towards zero but at a slower rate than in previous versions, reaching $50 \%$ of the $2045-$ 2050 value in the last projection period. The justification for the use of a convergencetowards-zero assumption appears to be twofold. First, the use of net migration counts in population projection models makes it possible to project a negative population. With a convergence-towards-zero assumption this is unlikely to happen, as the size of net migration shrinks. Second, zero net migration is taken as a default value due to lack of knowledge of the long-run future of migration in all countries. These justifications are discussed below.

Unlike a projection model based on migration rates, net migration counts bear no relation to the population at risk. Consequently, a migration count measure is unable to respond to changes in population size or structure. This could be problematic in a shrinking population with low fertility, as a projection model based on net migration counts might depopulate the country. For example, consider an elderly country with low fertility and high levels of net emigration. In the long run if the number of emigrants remains constant a projection model can potentially result in a negative population, as it continuously subtracts migrants in each future period regardless of the population at risk. By shrinking future net migration towards zero, demographers avoid this potential hazard.

\footnotetext{
${ }^{3}$ Note that the use of the label 'zero migration' for this scenario is slightly misleading. A better label might be 'balanced migration,' where net migration is zero in all countries (the number of immigrants over each period matches the number of emigrants in all countries) as opposed to there being no (zero) migration.
} 
Both the UN and demographers at WiC share the common practice of converging migration in all countries towards zero after 2050. This effectively subdues the role of migration as a component of population change and can be considered an unsatisfactory practice for two reasons. First, demographic scholars such as Coleman (2004) and Chamie (2016) (amongst others) have noted that mass migration, or at least migration pressure, is a growing influence in many countries and is unlikely to end in 2050. In the absence of new effective policies to stem it, migration will continue to make substantial contributions to populations in both Northern America and Western Europe. Second, the convergence towards zero adjustment is justified in the WPP literature by a complete lack of knowledge concerning future migration after 2050 (United Nations Department of Economic and Social Affairs Population Division 2016). This justification is flawed, as it uses a probabilistic statement on uncertainty in relation to a deterministic scenario. Zero net migration, as with any other value of net migration, should not be considered as a representation of uncertainty.

There are additional implications when demographers adopt a net migration scenario with trajectories towards zero in all countries: (1) migration will have a declining influence on population change; (2) the beginning and end of the convergence towards zero net migration will occur at the same time and at a constant speed in all countries; and (3) at the end of the convergence the global migration system will be in perfect balance, with all countries having equal numbers of immigrants and emigrants. This last implication is particularly unusual in a historical context: There is no precedent of a global migration system in perfect balance, nor is there any indication in the recent data of a convergence towards such a state during recent periods.

These unsatisfactory consequences suggest that it is necessary to explore alternative scenarios of net migration in projection models. To this end, in the remainder of this paper we develop alternative long-run net migration assumptions that (1) provide a range of scenarios to help illustrate the role of migration in projected populations and (2) are more relevant to possible policy concerns than those currently employed by demographers.

\section{Alternative long-run migration scenarios}

In recent years the development of future migration scenarios has become more sophisticated. As part of the International Futures Project, the Organisation for Economic Co-Operation and Development developed five scenarios to help assess how migration flows might evolve in the coming years up until 2030, and their important economic and social implications (OECD 2009). The Global Migration Futures project developed a framework for constructing migration scenarios (Paoletti, de Haas, and 
Vargas-Silva 2010) and looked in depth at potential trends in selected regions. However, none of these narrative-based scenarios involved quantifying future levels of long-run migration or entering them into a population projection model to measure potential demographic impacts.

Motivated by demand from the climate change community, O'Neill et al. (2014) detailed the Shared Socioeconomic Pathways (SSP), a set of five alternative narratives to describe possible world futures up to 2100 . The SSPs enable a common set of assumptions in social and climate sciences to help facilitate integrated research and assessment. Each narrative provides descriptive assumptions of future demographic outcomes alongside other elements such as human development, economy and lifestyle, policies and institutions, technology and environment, and natural resources. The narratives represent positions in a two-dimensional space, based on a scale of future socioeconomic challenges for adaptation to climate change and a scale of future socioeconomic challenges for mitigation from climate change.

Demographers based at WiC applied multidimensional demographic methods to project national populations based on alternative assumptions of future fertility, mortality, migration, and educational transitions that correspond to the five SSPs (KC and Lutz 2014; Lutz, Butz, and KC 2014; Sander, Abel, and Riosmena 2014). Migration was projected based on assumptions of immigration and emigration rates, derived in the base period from estimates of bilateral migration flows obtained using the methodology of Abel and Sander (2014). Up until 2050, immigration and emigration rates take high (SSP5), medium (SSP1, SSP2 and SSP4), or low (SSP3) levels after some short-run adjustments. Thereafter, immigration and emigration levels are adjusted so that the residual net migration converges to zero by $2095-2100$, following the lead of the UN.

A closer inspection of the SSP literature and its discussion of migration reveals that the convergence of net-migration-to-zero assumptions, used by KC and Lutz (2014) in all SSPs, does not fully reflect the different narratives. Table 1 shows extracts of mentions of migration from the detailed description of the SPP narratives in O'Neill et al. (2017). None of these imply a global migration system in perfect balance (with zero net migration in all countries) or convergence towards a similar state. 
Table 1: References to migration in each SSP in the supplementary materials of O'Neill et al. (2017)

\author{
SSP1: Sustainability - Taking the Green Road \\ Migration is at intermediate levels. Although increasing integration of labour markets allows \\ people to move around more freely, improved regional livelihoods and the renewed emphasis on \\ regional production reduce migration incentives.

\section{SSP2: Middle of the Road} \\ Migration between countries continues at intermediate levels owing to the restriction of labour \\ markets, but there are intermittent periods of greater international migration when populations \\ are challenged by food insecurity, conflict, and other factors.

\section{SSP3: Regional Rivalry - A Rocky Road} \\ In high-income countries, economic uncertainty leads to low fertility. Combined with low levels of \\ international migration, this leads to rapid ageing in industrialized countries. \\ SSP4: Inequality - A Road Divided \\ Migration is high for richer groups, but difficult for low-income groups \\ SSP5: Fossil-Fuelled Development - Taking the Highway \\ Migration from poorer to wealthier countries buffers the effect of ageing populations in \\ industrialized countries.
}

In the remainder of this section we propose alternative migration scenarios based on net migration counts. In combination with the UN medium migration scenario, the new assumptions allow for a better understanding of the range of potential future populations. Further, these scenarios are directly linked to SSP narratives via available GDP projections for each future pathway. The proposed migration scenarios could also be of potential use in answering common 'what if' type questions that policymakers and other users of population projections might ask.

Our new migration scenarios are developed in two stages. The first stage is based on a persistence assumption that is related to SSP2. In the second stage the other SSPs are developed in relation to SSP2 using existing SSP projections for Gross Domestic Product (GDP).

\title{
4.1 Persistence scenario (SSP2)
}

The SSP literature suggests that the SSP2 ('Middle of the Road') narrative represents a future where current trends continue more or less at levels observed in the recent past. Global emissions are projected to more or less follow recent trends, and whilst there are substantial challenges for mitigation and adaptation, neither is particularly severe (O'Neill et al. 2017). In order to reflect this future we use a persistence assumption: The 
net migration estimate in WPP2017 for the 2010-2015 period is assumed to remain constant throughout the entire projection period. This assumption was implemented in all countries except the Central African Republic, Lebanon, Libya, Oman, Syria, and Turkey. In these six nations the persistence value was set to the 2005-2010 net migration count, as during the 2010-2015 period net migration levels were extreme in comparisons with their historical values. The criteria for an extreme level were based on country-specific Z-scores (based on net migration counts between 1950-1955 and 2010-2015) reaching above plus or minus 2.5. As the substitutions created a non-zero sum of global net migration, small proportional adjustments were made in all countries.

The implementation of our persistence assumption in a global population projection model has a number of other useful benefits besides the link with the SSP2. First, the results can be used to conduct a comparison with the UN medium scenario. This allows for a quantification of the role of UN experts in their population projections when setting future levels of net migration, both before and after their post-2050 convergence-towards-zero trajectory. Second, in many economic and financial time series applications the use of a naive forecast - i.e., a persistence assumption - for complex processes has been found to perform better than, or similar to, alternatives based on intricate forecasting models (Hyndman and Athanasopoulos 2013). Third, the persistence assumption matches a similar scenario used by the US Census Bureau for their long-run population projections (which stop at 2050).

\subsection{Other scenarios (SSP1, SSP3, SSP4, and SSP5)}

Developing net migration scenarios can only be undertaken by adjusting the balance of each country in the migration system. As global net migration must sum to zero it is not possible to operationalize a scenario using net migration counts where, for example, there is increasing migration in all countries. If all countries witnessed an increase in net migration a global net migration balance of zero would no longer exist; hence an increase in net migration counts in one country must be counterbalanced by decreases elsewhere.

With this restriction in mind, we created migration scenarios for the remaining SSPs by linking them to relative changes in future shares of global economic wealth, a factor that is closely associated with international migration. Dellink et al. (2017) and Crespo Cuaresma (2017) have recently developed separate economic projections for the SSPs. We utilize the results from the former of these SSP projections, as the latter is (1) closely linked to the human capital projections of K.C. and Lutz (2014) that have existing migration assumptions, and (2) covers fewer countries than Dellink et al. (2017). 
The future SSP scenarios by Dellink et al. (2017) for GDP (in 2005 US\$) in each continent are shown in the left hand column of Figure $1 .{ }^{4}$ In some scenarios, such as SSP5, GDP is increasing in all areas at a fast pace. As mentioned, it is not possible to develop net migration scenarios that simply match these increases, as global net migration must sum to zero. Hence, a process to link future net migration to changes in future shares of global economic wealth was undertaken. This involved calculating future SSP1, SSP3, SSP4, and SSP5 shares of global economic wealth relative to the shares of global economic wealth in SSP2. The trajectories of these shares were then used to scale up or down the net migration assumption of SSP2 in each of the remaining SSPs. The amplitude of our scaling was based on historic variation in past net migration flows to ensure that future net migration trajectories are bounded to sensible ranges. A final rescaling was carried out to ensure that the global net migration sums to zero in all countries. Full technical details of the process to derive net migration trajectories in SSP1, SSP3, SSP4, and SSP5 are provided in the Appendix.

\subsection{Net migration trajectories}

The net migration trajectories, summed to the continental level for each set of SSPs, are shown in the middle column of Figure 1, accompanied by the historic net migration and future assumptions used by the UN in WPP2017. In all countries (and continents) the SSP2 is fixed at the last observed level. In the other scenarios the trajectories of net migration are set relative to the change in GDP in SSP2 (plotted in the left-hand column in Figure 1). The linkage between the GDP and net migration trajectories are most clearly visible for SSP5 ('Fossil-Fuelled Development - Taking the Highway'). In all continents, GDP increases rapidly over time. However, relative to SSP2, in the first half of the projection period the increases in GDP are fastest in Asia and Africa, and in the second half (where the gap between the GDP of SSP2 and SSP5 increasingly widens) are faster in Europe, North America, and Oceania. This results in net migration first rising in Asia and Africa and then declining thereafter, matched by decreases in net migration in Europe and North America followed by rapid increases.

\footnotetext{
${ }^{4}$ Figure produced using ggplot2 package (Wickham 2009) in R (R Development Core Team 2016).
} 
Abel: Non-zero trajectories for long run net migration assumptions in global population projection models

Figure 1: GDP and linked Net Migration SSP assumptions aggregated to continental regions with associated projected population totals
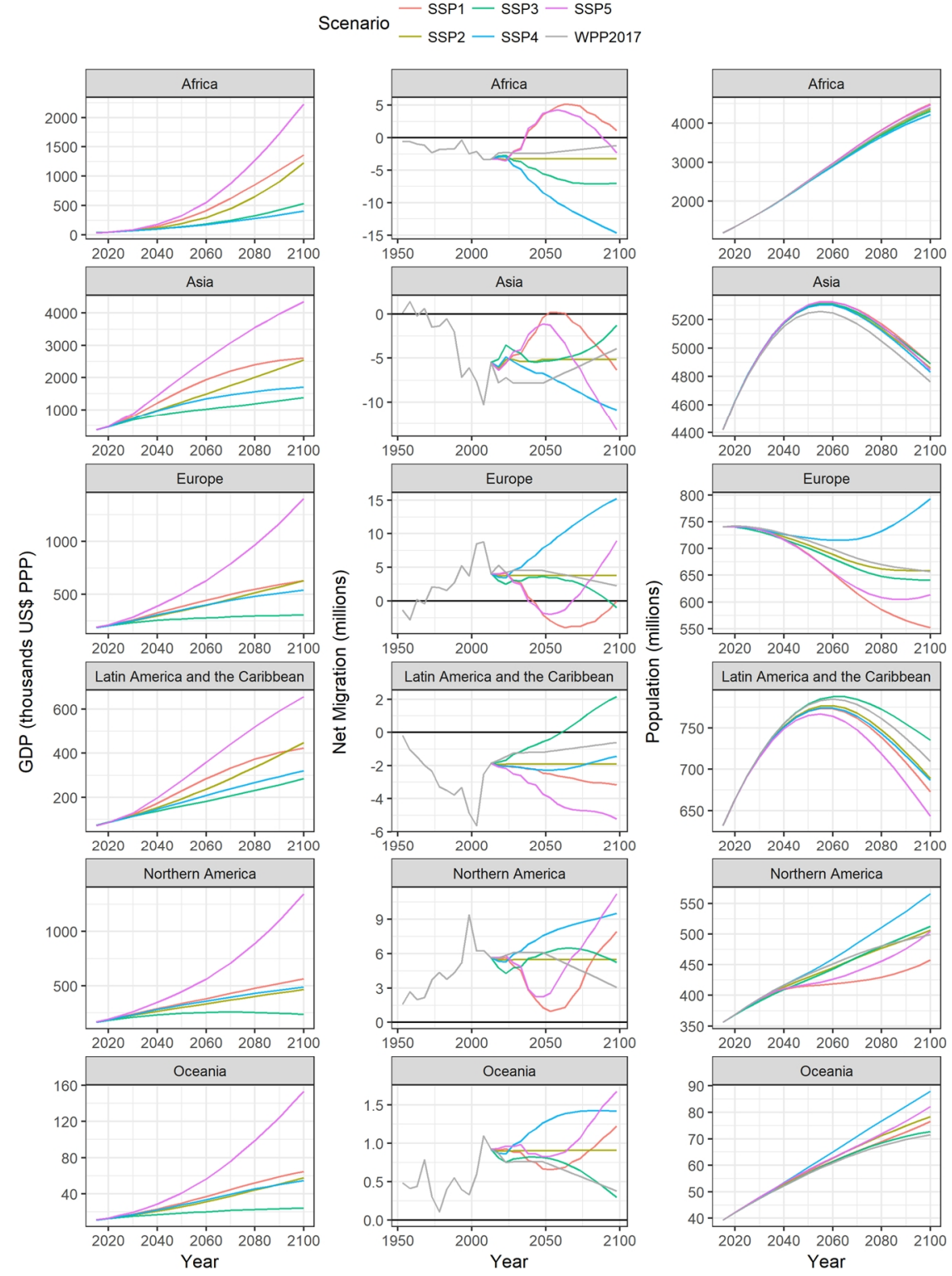
Within each continent there are distinct differences in trajectories, as described in Table 2. For, example, in SSP5, Southern Africa follows a similar pattern to that shown in Figure 1 for Latin America, where as in Eastern Europe net migration undergoes a continuous decline in the second half of the projection period.

Table 2: $\quad$ SSP net migration trajectories ${ }^{5}$

\begin{tabular}{|c|c|c|c|c|}
\hline \multirow[t]{2}{*}{ Continent } & \multicolumn{4}{|c|}{ Scenario } \\
\hline & $\begin{array}{l}\text { SSP1: Sustainability - } \\
\text { Taking the Green Road }\end{array}$ & $\begin{array}{l}\text { SSP3: Regional rivalry - } \\
\text { A Rocky Road }\end{array}$ & $\begin{array}{l}\text { SSP4: Inequality - } \\
\text { A Road Divided }\end{array}$ & $\begin{array}{l}\text { SSP5: Fossil-fuelled } \\
\text { development - } \\
\text { Taking the Highway }\end{array}$ \\
\hline Africa & $\begin{array}{l}\text { Increasing net migration to } \\
\text { positive levels in Northern, } \\
\text { Eastern, Middle, and } \\
\text { Western Africa, peaking } \\
\text { around } 2070-2075 . \\
\text { Gradual declines in } \\
\text { Southern Africa net } \\
\text { migration throughout } \\
\text { period. }\end{array}$ & $\begin{array}{l}\text { Further declines of net } \\
\text { migration in Eastern, } \\
\text { Middle, and Western } \\
\text { Africa. Small declines in } \\
\text { net migration in Northern } \\
\text { and Southern Africa until } \\
2060-2065 \text { and then } \\
\text { rising levels thereafter. }\end{array}$ & $\begin{array}{l}\text { Steep declines in net } \\
\text { migration away from } \\
\text { Eastern, Northern, and } \\
\text { Western Africa throughout } \\
\text { period. Shallower } \\
\text { declines in Middle Africa. } \\
\text { Stable net migration } \\
\text { trajectory for Southern } \\
\text { Africa. }\end{array}$ & $\begin{array}{l}\text { Similar trajectories as } \\
\text { SSP1 in Eastern, } \\
\text { Middle, and Western } \\
\text { and Southern Africa with } \\
\text { earlier peaks in the } \\
\text { former three. } \\
\text { Persistence-level net } \\
\text { migration in Northern } \\
\text { Africa until 2055-2060; } \\
\text { falling levels thereafter. }\end{array}$ \\
\hline Asia & $\begin{array}{l}\text { Steep increases in net } \\
\text { migration in South-Central } \\
\text { and South-Eastern Asia } \\
\text { until } 2060-2065 \text {, with } \\
\text { equally steep declines } \\
\text { thereafter until 2100. Steep } \\
\text { declines in net migration in } \\
\text { Western Asia until 2060- } \\
2065 \text {, steady thereafter. } \\
\text { Small gentle declining } \\
\text { trajectory of net migration } \\
\text { in Eastern Asia. }\end{array}$ & $\begin{array}{l}\text { Rising net migration in } \\
\text { Eastern, South-Eastern, } \\
\text { and Western Asia, with } \\
\text { especially large increases } \\
\text { in the latter half of the } \\
\text { projection period in } \\
\text { South-Eastern Asia. Slow } \\
\text { falling net migration in } \\
\text { South-Central Asia. }\end{array}$ & $\begin{array}{l}\text { Steep declines in net } \\
\text { migration in South-Central } \\
\text { and South-Eastern Asia } \\
\text { throughout trajectory. } \\
\text { Steep increases in net } \\
\text { migration in Eastern and } \\
\text { Western Asia. }\end{array}$ & $\begin{array}{l}\text { Small increases in net } \\
\text { migration in South- } \\
\text { Central and South- } \\
\text { Eastern Asia in the first } \\
\text { half of the projection } \\
\text { period and then falls } \\
\text { thereafter. Small } \\
\text { declines in net migration } \\
\text { in Western Asia } \\
\text { throughout period. } \\
\text { Declining net migration } \\
\text { in Eastern Asia in first } \\
\text { half of projection period, } \\
\text { then stable. }\end{array}$ \\
\hline Europe & $\begin{array}{l}\text { Declining net migration in } \\
\text { all regions in first half of } \\
\text { projection period followed } \\
\text { by similar-sized increase in } \\
\text { second half in all regions } \\
\text { but Eastern Europe - } \\
\text { where net migration } \\
\text { continues to decline in the } \\
\text { second half of the } \\
\text { projection period. }\end{array}$ & $\begin{array}{l}\text { Persistence level of net } \\
\text { migration until } 2045-2050 \\
\text { in all regions, then falling } \\
\text { net migration in Northern, } \\
\text { Southern, and Western } \\
\text { Europe for the rest of the } \\
\text { projection period. } \\
\text { Increasing net migration } \\
\text { in Eastern Europe in the } \\
\text { second half of the } \\
\text { projection period. }\end{array}$ & $\begin{array}{l}\text { Increasing net migration } \\
\text { trajectories throughout the } \\
\text { period. }\end{array}$ & $\begin{array}{l}\text { Similar trajectories as } \\
\text { SSP1 but with increases } \\
\text { setting in earlier and } \\
\text { rising to higher levels in } \\
\text { the latter part of the } \\
\text { projection period in } \\
\text { Northern, Southern, and } \\
\text { Western Europe. }\end{array}$ \\
\hline
\end{tabular}

${ }^{5}$ In SSP2 ('Middle of the Road'), net migration trajectories persist at 2010-2015 levels throughout the projection period. 
Table 2: (Continued)

\begin{tabular}{|c|c|c|c|c|}
\hline \multirow[t]{2}{*}{ Continent } & \multicolumn{4}{|c|}{ Scenario } \\
\hline & $\begin{array}{l}\text { SSP1: Sustainability - } \\
\text { Taking the Green Road }\end{array}$ & $\begin{array}{l}\text { SSP3: Regional rivalry - } \\
\text { A Rocky Road }\end{array}$ & $\begin{array}{l}\text { SSP4: Inequality - } \\
\text { A Road Divided }\end{array}$ & $\begin{array}{l}\text { SSP5: Fossil-fuelled } \\
\text { development - } \\
\text { Taking the Highway }\end{array}$ \\
\hline $\begin{array}{l}\text { Latin America } \\
\text { and the } \\
\text { Caribbean }\end{array}$ & $\begin{array}{l}\text { Small steady declines of net } \\
\text { migration in Central and } \\
\text { Southern America. } \\
\text { Fluctuations around } \\
\text { persistence levels of net } \\
\text { migration in Caribbean. }\end{array}$ & $\begin{array}{l}\text { Increasing net migration } \\
\text { trajectories throughout the } \\
\text { period. }\end{array}$ & $\begin{array}{l}\text { Small gradual increases } \\
\text { in net migration. }\end{array}$ & $\begin{array}{l}\text { Steep declines in net } \\
\text { migration in first half of } \\
\text { projection period, } \\
\text { followed by shallower } \\
\text { declines in second half. }\end{array}$ \\
\hline North America & $\begin{array}{l}\text { Declining net migration in } \\
\text { first half of projection period } \\
\text { followed by similar-sized } \\
\text { increase in second half. }\end{array}$ & $\begin{array}{l}\text { Small gradual fluctuations } \\
\text { of net migration around } \\
\text { persistence levels. }\end{array}$ & $\begin{array}{l}\text { Steady increase in net } \\
\text { migration throughout } \\
\text { period. }\end{array}$ & $\begin{array}{l}\text { Similar trajectories as } \\
\text { SSP1 but with increases } \\
\text { setting in earlier and } \\
\text { rising to higher levels in } \\
\text { the latter part of the } \\
\text { projection period. }\end{array}$ \\
\hline Oceania & $\begin{array}{l}\text { Small declines in net } \\
\text { migration in first half of } \\
\text { projection period, followed } \\
\text { by faster increases in } \\
\text { second half. }\end{array}$ & $\begin{array}{l}\text { Declines in net migration } \\
\text { in the second half of the } \\
\text { projection period. }\end{array}$ & $\begin{array}{l}\text { Large increases in net } \\
\text { migration in first half of } \\
\text { projection period, which } \\
\text { remains at high levels } \\
\text { during the second half. }\end{array}$ & $\begin{array}{l}\text { Similar trajectories as } \\
\text { SSP1 but with increases } \\
\text { setting in earlier and } \\
\text { rising to higher levels in } \\
\text { the latter part of the } \\
\text { projection period. }\end{array}$ \\
\hline
\end{tabular}

The net migration trajectory for SSP1 ('Taking the Green Road') is a less extreme version of SSP5 in many areas, with a rising net migration in parts of Asia and Africa offset by falling net migration in Europe and North America during the first half the projection period, which then flips in the second half of the period due to shifts in the relative shares of global economic wealth. In SSP3 ('Regional Rivalry'), net migration in many countries follows levels similar to the SSP2 equivalent in the first half of the projection period. In the second half of the projection period, Europe and Oceania see falls in net migration balanced by gains in Asia and Latin America. In SSP4 ('Inequality - A Road Divided'), net migration quickly increases in Europe, North America, and Oceania throughout the period, offset by declines in Africa and Asia.

\section{Population projection under alternative migration scenarios}

We used the assumed future net migration counts in each of the SSP scenarios described in Section 4 as inputs in a global cohort component population projection model based on net migration counts. This allows for two comparisons: (1) comparison of the effect of SSP net migration scenarios and their potential effect on future 
populations, and (2) comparison of the SSP2 persistence assumption with the WPP2017 assumption. ${ }^{6}$ This latter comparison quantifies the effect of expert judgment used by the UN in setting (1) country-specific adjustments in the short run, (2) country-specific medium-run levels of net migration set up until 2045-2050, and 3) the global convergence towards zero trend after 2045-2050.

Net migration counts for each age and gender group, required for the cohort component model, were obtained by applying the corresponding country- and periodspecific proportional disaggregation found in the WPP2017 medium assumption. ${ }^{7}$ Projections were performed using the pop.predict() function in the bayesPop package (Ševčíková and Raftery 2014, 2016) for R. In each projection the medians of the UN probabilistic forecasts of fertility and mortality were used by setting the number of trajectories to one. Projections for all countries up until 2100 were then obtained.

The SSP net migration assumptions provide a range of alternative projected population outcomes, as shown in the right hand column of Figure 1. In Africa the 2100 population ranges from 4,219 million under SSP4 to 4,493 million under SSP1. The WPP2017 projection is within this range: 4,400 million in 2100. In Figure 2 the differences in the population projected by the WPP2017 net migration assumptions and each of the SSP net migration assumptions are plotted. In Africa only the projected population of the Southern Africa region is noticeably impacted by alternative net migration assumptions. In this region the 2100 projected populations for the SSPs are between 12\% (SSP5) and 17\% (SSP3) higher than those obtained from the WPP2017 assumptions. The most noticeable difference is in the underlying net migration assumptions for South Africa, where the UN assumes immediate declines in net migration to 100,000 from much higher levels observed in the recent past. The SSP scenarios have higher net migration, as SSP2 is based on a persistence assumption (net migration was estimated to be above 500,000 in four of the five most recent five-year periods) and the other SSPs are set up relative to the persistence level.

\footnotetext{
${ }^{6}$ Note: WPP2017 projection refers throughout this section to the default population projections returned by the pop.predict() function, rather than the official data in the DVD of the United Nations Department of Economic and Social Affairs Population Division (2017). Outputs from the R package do not always match official UN figures. These discrepancies are due to a variety of reasons, such as the lack of publicly available data on fertility, mortality, and migration for smaller nations and of age-specific net migration counts for all countries.

${ }^{7}$ Obtained by applying the age.specific.migration() function in the wpp $2017 \mathrm{R}$ package.
} 
Figure 2: Comparison of UN WPP projected populations in 2100 with alternative projection populations using SSP net migration levels

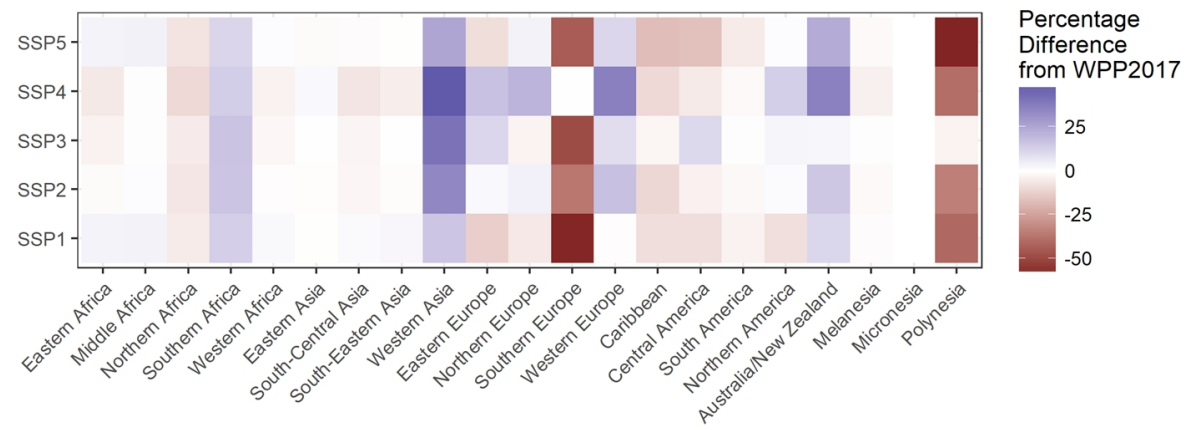

In Asia the future 2100 population ranges from 4,830 million in SSP4 to 4,891 million in SSP3 (see Figure 1). Projected populations in all SSP scenarios are higher than the equivalent projected population of 4,763 million under the WPP2017 assumptions. This lower population is driven by the far lower levels of negative net migration assumed by the UN: The SSP2 scenario assumes a net migration of -5.4 million migrants in each five-year period before 2050, compared to -7.82 million in WPP2017. While at the continental level the comparative differences might appear minor relative to the overall population size, there are larger differences at smaller geographic levels where intra-Asian migration trends are not aggregated and countries where international migration plays a key role in population change are not overwhelmed by population giants such as China and India. As shown in Figure 2, in Western Asia, home to countries with large positive net migration in recent decades, such as Saudi Arabia, the United Arab Emirates, and Qatar, the 2100 population is 35\% higher when using the SSP2 persistence assumption than the WPP2017 projection. The highest overall population for Western Asia was obtained from SSP3, where the 2100 population is $49 \%$ higher than the equivalent WPP2017 population. The large differences are generated by comparatively low levels of net migration in WPP2017 for oil-rich Gulf States, assumed with near immediate effect.

In Europe the SSP net migration assumptions lead to some drastic differences in projected population trajectories, ranging from 5,520 million in SSP1 to 793 million in SSP4 (shown in Figure 1). The equivalent projected population from WPP2017 net migration assumptions was 657 million. In all scenarios the population declines from the 2015 base year. However, in SSP5 the projected population hits a minimum before 2090 and then increases once more. The greatest disparities between the 2100 SSP and WPP2017 projected populations occur in Southern Europe where the SSPs have lower 
totals (the most extreme being 59\% lower in SSP1), and Western Europe where the SSP populations are higher (the most extreme being 37\% higher in SSP4).

In Latin America and the Caribbean each projected population follows a similar trajectory of a peak around 2060 and a decline thereafter (see Figure 1). In all but SSP3, the SSP projections for 2100 populations are lower than equivalent WPP2017 totals. The differences are greatest in the Caribbean region, most noticeably in SSP5 (Figure 2 ), where the 2100 projected population is $17 \%$ lower than in WPP2017.

In Northern America the different SSP net migration assumptions have a large influence on the projected population. The SSP2 persistence assumption has a similar 2100 population total to the WPP2017 projection, despite differences in the underlying net migration trajectories. This 2100 projected population falls almost midway between the SSP1 and SSP4 projections of 457 million and 566 million respectively (Figure 1).

Finally, in Oceania all SSP net migration assumptions lead to higher population totals in 2100 than WPP2015 assumptions (Figure 1). The higher populations are almost entirely in Australia and New Zealand, where in SSP4 the 2100 population is $37 \%$ higher than the WPP2017 projection. In SSP5, the fossil-fuelled development narrative, there is a $59 \%$ decline in the Polynesian population, related to sharp falls in share of the global economic wealth.

\section{Discussion}

Future assumptions of international migration are a necessary component of global population projection exercises. Typically, the effect of migration in the long run is subdued by assuming a convergence towards zero net migration in all countries. As we explored in this paper, this assumption has a number of potential weaknesses. There appears to be no overwhelming justification for the convergence-towards-zero assumption when recent work on forecasting long-run migration ignores the assumption (Azose and Raftery 2015; Cohen 2012) and studies on the role of migration in the UN projections suggest it is very unlikely (Billari and Dalla-Zuanna 2013), as does the UN Population Division itself (United Nations Department of Economic and Social Affairs Population Division 2016). The end state of zero net migration in all countries has not been observed in recorded human history. Data in the recent past shows no tendency towards such a future.

The convergence towards a zero-net-migration assumption is typically implemented as a linear rise or fall, beginning and ending at the same time in each country. It is a relatively complex assumption when compared to the persistence assumption (SSP2) explored in this paper. It inherently implies a turning point in the trends of net migration in all countries. For example, net migration in countries such as 
the United States or Australia has been continuously positive for many decades. In the future, migration patterns in these traditional receiving countries will dramatically change as net migration falls toward zero. Such complexity might be unwarranted, given the lack of consensus by scholars on the long-run future of migration patterns. Further, in other complex forecasting settings, naïve forecasts, analogous to a persistence assumption, have been relatively successful in comparison to more complex models.

The use of multiple migration scenarios illustrates some future potential variation in population projections from migration that is not provided for when considering a single variant, as used by the UN. For example, in Europe the SSP projections proposed in this paper show a range of projected population trajectories, some of which do not imply a continued decline in the European population. Due to the deep levels of complexity in the global migration system and uncertainty as to future directions, the use of scenarios appears to be an appropriate tool. Similar scenario-based approaches are the dominant approach in projections of other complex systems such as climate change, where realistic probabilistic measures of uncertainty can become overwhelming and are unable to reflect policy-relevant narratives.

The alternative scenarios proposed in this paper were constructed to align the longrun migration futures described in the SSP narratives. Unlike KC and Lutz (2014), migration in each SSP was not set on a trajectory to reach zero during the last projection period for all countries, allowing the full role of migration to be borne by the end of the projection period. Net migration levels of the SSP2 - the 'Middle of the Road' narrative - were set to persist throughout the projection period, which then allowed other SSPs to track relative changes in country shares of global economic wealth, obtained from existing SSP projections of GDP. In some extreme cases, in small island states this leads to shrinking populations by 2100 under the SSP5 narrative, 'Fossil Fuelled Development.' Less dramatic effects could be obtained by tweaking the multiplier (to values less than two when implemented in Step 3 of the methodology) used to scale the limits for the non-SSP2 future net migration levels from the persistence assumption. One might also experiment with the construction of the persistence assumptions, such as taking an average over a historic range of periods.

Future work on migration scenarios for global population projections might involve similar linkages of existing SSP measures to more detailed measures of migration. Recent estimates of past global bilateral migration (Abel 2013, 2017; Abel and Sander 2014) could be utilized. This would allow for a full multi-regional global population projection model (as proposed by Cohen et al. (2008) or a simpler biregional model (as implemented in Abel, KC, and Sander (2013) and Lutz et al. (2014)), rather than a projection model based on net migration counts. One possible procedure to link migration and the existing SSP literature is to build a regression-type 
model for the relationship of past bilateral migration flows with past drivers of migration such as distance, cultural similarity, language, population size and structure, human capital, income inequality, migration, and aging policies. Where SSP measures of the migration driver variable exist or the variable itself is time-invariant (e.g., distance), projections of bilateral migration can be generated using parameter estimates from the fitted models based on past data. In different SSP scenarios the parameters might be set to increase or decrease future migration levels to better reflect the narrative in the context of migration.

Formulating long-run assumptions for international migration is a difficult but necessary task when carrying out global population projection models. The additional long-run migration scenarios presented in this paper provide plausible alternative trajectories for future populations with a direct link to the existing economic projections of the SSPs. Further, the alterative scenarios reveal where long-run migration assumptions have a major influence in global population projection models, a feature commonly missing in current assumptions.

\section{Acknowledgments}

This work was supported by National Science Foundation of China Research Fund for International Young Scientists. The author is grateful for suggestions provided by the Associate Editor and three anonymous reviewers as well as Patrick Gerland for feedback on the data section of a much much earlier draft of the paper. 


\section{References}

Abel, G.J. (2013). Estimating global migration flow tables using place of birth data. Demographic Research 28(18): 505-546. doi:10.4054/DemRes.2013.28.18.

Abel, G.J. (2017). Estimates of global bilateral migration flows by gender between 1960 and 2015. International Migration Review. doi:10.1111/imre.12327.

Abel, G.J., K.C., S., and Sander, N. (2013). Examining the role of international migration in global population projections. Rome: Eurostat and UNECE (Joint Eurostat/UNECE Work Session on Demographic Projections No. 14). http://www.unece.org/fileadmin/DAM/stats/documents/ece/ces/ge.11/2013/WP_ 14.1_02.pdf.

Abel, G.J. and Sander, N. (2014). Quantifying global international migration flows. Science 343(6178): 1520-1522. doi:10.1126/science.1248676.

Azose, J.J. and Raftery, A.E. (2015). Bayesian probabilistic projection of international migration. Demography 52(5): 1627-1650. doi:10.1007/s13524-015-0415-0.

Azose, J.J., Ševčíková, H., and Raftery, A.E. (2016). Probabilistic population projections with migration uncertainty. Proceedings of the National Academy of Sciences 113(23): 6460-6465. doi:10.1073/pnas.1606119113.

Bijak, J. (2011). Forecasting international migration in Europe: A Bayesian view. Dordrecht: Springer Netherlands. doi:10.1007/978-90-481-8897-0.

Bijak, J. (2012). Migration assumptions in the UK National Population Projections: Methodology review [electronic resource]. Southampton: Office for National Statistics. http://www.ons.gov.uk/ons/guide-method/method-quality/specific/ population-and-migration/population-projections/npp-migration-assumptionsmethodology-review/index.html.

Bijak, J. and Wiśniowski, A. (2010). Bayesian forecasting of immigration to selected European countries by using expert knowledge. Journal of the Royal Statistical Society, Series A: Statistics in Society 173(4): 775-796. doi:10.1111/j.1467985X.2009.00635.x.

Billari, F.C. and Dalla-Zuanna, G. (2013). Cohort replacement and homeostasis in world population, 1950-2100. Population and Development Review 39(4): 563585. doi:10.1111/j.1728-4457.2013.00628.x.

Booth, H. (2006). Demographic forecasting: 1980 to 2005 in review. International Journal of Forecasting 22(3): 547-581. doi:10.1016/j.ijforecast.2006.04.001. 
Buettner, T. and Muenz, R. (2016). Comparative analysis of international migration in population projections. Washington, D.C.: Global Knowledge Partnership on Migration and Development (KNOMAD Working Paper Series No. 10). https://www.knomad.org/sites/default/files/2017-04/KNOMAD\%20WP\%2010 \%20Comparative $\% 20$ Analysis\%20of\%20International\%20Migration $\% 20 \mathrm{in} \% 20$ Population\%20Projections.pdf.

Chamie, J. (2016, September 27). Prepare for the $21^{\text {st }}$ century exodus of migrants. New Haven: YaleGlobal Online. http://yaleglobal.yale.edu/content/prepare-21stcentury-exodus-migrants.

Cohen, J.E. (2012). Projection of net migration using a gravity model. In: Tenth coordination meeting on international migration. New York: Population Division, Department of Economic and Social Affairs, United Nations: 1-8.

Cohen, J.E., Roig, M., Reuman, D.C., and GoGwilt, C. (2008). International migration beyond gravity: A statistical model for use in population projections. Proceedings of the National Academy of Sciences 105(40): 15269-15274. doi:10.1073/pnas.0808185105.

Coleman, D.A. (2004). World population in 2300: A century too far? In: World population to 2300. New York: Population Division, Department of Economic and Social Affairs, United Nations: 127-136.

Crespo Cuaresma, J. (2017). Income projections for climate change research: A framework based on human capital dynamics. Global Environmental Change 42: 226-236. doi:10.1016/j.gloenvcha.2015.02.012.

Dellink, R., Chateau, J., Lanzi, E., and Magné, B. (2017). Long-term economic growth projections in the shared socioeconomic pathways. Global Environmental Change 42: 200-214. doi:10.1016/j.gloenvcha.2015.06.004.

Howe, N. and Jackson, R. (2004). Projecting immigration: A survey of the current state of practice and theory. Chestnut Hill: Center for Retirement Research at Boston College (CRR WP No. 2004-32). http://crr.bc.edu/wp-content/uploads/2004/12/ wp_2004-32.pdf.

Hyndman, R.J. and Athanasopoulos, G. (2013). Forecasting: Principles and practice. Melbourne: OText. http://otexts.com/fpp/.

K.C., S. and Lutz, W. (2014). The human core of the shared socioeconomic pathways: Population scenarios by age, sex and level of education for all countries to 2100 . Global Environmental Change 42: 118-192. doi:10.1016/j.gloenvcha.2014.06. 004. 
Kelly, J.J. (1987). Improving the comparability of international migration statistics: Contributions by the Conference of European Statisticians from 1971 to date. International Migration Review 21(4): 1017-1037. doi:10.2307/2546502.

Kupiszewska, D. and Nowok, B. (2008). Comparability of statistics on international migration flows in the European Union. In: Willekens, F. and Raymer, J. (eds.). International migration in Europe: Data, models and estimates. London: Wiley: 41-73.

Lee, R.D. (2011). The outlook for population growth. Science 333(6042): 569-573. doi:10.1126/science.1208859.

Lutz, W. (1991). Future demographic trends in Europe and North America: What can we assume today? London: Academic Press.

Lutz, W., Butz, W.P., and K.C., S. (2014). World population and human capital in the $21^{\text {st }}$ century. Oxford: Oxford University Press.

Massey, D.S., Arango, J., Hugo, G.J., Kouaouci, A., Pellegrino, A., and Taylor, J.E. (1993). Theories of international migration: A review and appraisal. Population and Development Review 19(3): 431-466.

National Research Council (2000). Beyond six billion: Forecasting the world's population. Washington, D.C.: National Academy Press.

O’Neill, B.C., Kriegler, E., Ebi, K.L., Kemp-Benedict, E., Riahi, K., Rothman, D.S., and Solecki, W. (2017). The roads ahead: Narratives for shared socioeconomic pathways describing world futures in the $21^{\text {st }}$ century. Global Environmental Change 42: 169-180. doi:10.1016/j.gloenvcha.2015.01.004.

O’Neill, B.C., Kriegler, E., Riahi, K., Ebi, K.L., Hallegatte, S., Carter, T.R., and van Vuuren, D.P. (2014). A new scenario framework for climate change research: The concept of shared socioeconomic pathways. Climatic Change 122(3): 387400. doi:10.1007/s10584-013-0905-2.

OECD (2009). The future of international migration to OECD countries. Paris: OECD Publishing. doi:10.1787/9789264064126-en.

Paoletti, E., de Haas, H., and Vargas-Silva, C. (2010). Global Migration Futures: The concept and theory of migration scenarios. Oxford: International Migration Instuitute. http://www.imi.ox.ac.uk/pdfs/projects/gmf-pdfs/the-concept-and-theo ry-of-migration-scenarios. 
R Development Core Team (2016). R: A language and environment for statistical computing [electronic resource]. Vienna: The R Foundation for Statistical Computing. http://www.r-project.org/.

Rogers, A. (1990). Requiem for the net migrant. Geographical Analysis 22(4): 283300. doi:10.1111/j.1538-4632.1990.tb00212.x.

Sander, N., Abel, G.J., and Riosmena, F. (2014). The future of international migration. In: Lutz, W., Butz, B., and K.C., S. (eds.). World population and human capital in the $21^{\text {st }}$ century. Oxford: Oxford University Press: 333-397.

Ševčíková, H. (2017). wpp2017: World population prospects 2017: R package version 1.0-1 [electronic resource]. http://cran.r-project.org/package=wpp2017.

Ševčíková, H. and Gerland, P. (2013). wpp2010: World population prospects 2010: R package version 1.2-0 [eletronic resource]. http://cran.r-project.org/package= wpp2010.

Ševčíková, H., Gerland, P., Andreev, K., Li, N., Gu, D., and Spoorenberg, T. (2013). wpp2012: World Population Prospects 2012. R package version 2.2-1 [electronic resource]. http://cran.r-project.org/package=wpp2012.

Ševčíková, H. and Raftery, A.E. (2014). bayesPop: Probabilistic Population Projections: Version 5.0-0 [electronic resource]. http://cran.r-project.org/web/ packages/bayesPop/.

Ševčíková, H. and Raftery, A.E. (2016). bayesPop: Probabilistic Population Projections. Journal of Statistical Software 75(5). doi:10.18637/jss.v075.i05.

United Nations Department of Economic and Social Affairs Population Division (2014). World population prospects: The 2012 revision: Methodology of the United Nations Population Estimates and Projections. New York: Population Division, Department of Economic and Social Affairs, United Nations (ESA/P/WP No. ESA/P/WP.235). http://esa.un.org/unpd/wpp/Documentation/ pdf/WPP2012_Methodology.pdf.

United Nations Department of Economic and Social Affairs Population Division (2015b). wpp2015: World population prospects 2015. R package version 1.0-0 [electronic resource]. New York: Population Division, Department of Economic and Social Affairs, United Nations. http://cran.r-project.org/package=wpp2015. 
United Nations Department of Economic and Social Affairs Population Division (2016). International migration report 2015. New York: Population Division, Department of Economic and Social Affairs, United Nations. http://www.un.org/ en/development/desa/population/migration/publications/migrationreport/docs/Mi grationReport2015_Highlights.pdf.

United Nations Department of Economic and Social Affairs Population Division (2017). World population prospects: The 2017 revision, key findings and advance tables. New York: United Nations Department of Economic and Social Affairs/Population Division.

Wickham, H. (2009). ggplot2: Elegant graphics for data analysis. New York: Springer. doi:10.1007/978-0-387-98141-3.

Willekens, F. (1994). Monitoring international migration flows in Europe. European Journal of Population 10(1) : 1-42. doi:10.1007/BF01268210. 


\section{Appendix}

We undertook a four-step process to link future net migration to changes in future shares of global economic wealth.

1. Derive country $(c)$-period $(p)$ specific measures for shares for global economic wealth in each SSP $(s)$ based on the GDP estimates of Dellink et al. (2017):

$$
g_{c p}^{S}=\frac{G D P_{c p}^{S}}{\sum_{c} G D P_{c p}^{S}} .
$$

2. Calculate the relative size of the share of global GDP in each country-period and in each scenario (SSP1, SSP3, SSP4, and SSP5) relative to the corresponding SSP2 global GDP share.

$$
w_{c p}^{S}=\frac{g_{c p}^{S}}{g_{c p}^{S S P}} .
$$

This provides a basis for creating country period-specific future net migration assumptions relative to the SSP2 persistence assumption (where $w_{c p}^{S S P 2}=1$ ). For example, if a country gains a larger share of global economic wealth in SSP1 than in SSP2 (i.e., $w_{c p}^{S}>1$ ), then the assumed level of net migration in SSP1 is based on a scaled-up version of net migration SSP2 (persistence assumption).

3. The range of $w_{c p}^{S}$ is relatively small, with a standard deviation of 0.0659 in 20952100 across all counties and scenarios. When used as a multiplier for the SSP2 persistence values to derive non-SPP2 assumptions, the resulting differences are minor. This is due to differences in the measurement scales of relative GDP shares and net migration counts. In order to provide a more viable range of outcomes, $w_{c p}^{s}$ are rescaled to provide a range of net migration multipliers $\left(m_{c p}^{s}\right.$, with a lower boundary $l_{c}$ and an upper boundary $u_{c}$ ) over all SSPs and all periods, corresponding to plus and minus two standard deviations from the persistence level $\left(y_{c}^{S S P 2}\right)$ of net migration in each country, i.e.:

$$
\begin{aligned}
l_{c} & =\frac{\min _{S p} y_{c}}{y_{c}^{S S P 2}}, \text { where } \min _{s p} y_{c}=y_{c}^{S S P 2}-2 \sigma_{c}, \\
u_{c} & =\frac{\max _{S p} y_{c}}{y_{c}^{S S P 2}}, \text { where } \max _{s p} y_{c}=y_{c}^{S S P 2}+2 \sigma_{c} .
\end{aligned}
$$


Two was chosen as a multiplier for the standard deviations in order to provide bounds on the range for future net migration, based on past variation that covers approximately $95 \%$ of possible values. The range between the upper and lower bounds should not be interpreted as a statistical prediction interval, as they are to be used in a projection exercise and will be modified further in the next step. The country-specific standard deviations are based on non-extreme past net migration counts, where extreme values were based on Z-scores (past data with Z-scores greater than plus or minus 2.5 were dropped from the standard deviation calculation).

The ranges for new multiples are applied to rescale $w_{c p}^{S}$;

$$
m_{c p}^{s}=\frac{u_{c}-l_{c}}{\max _{s p} w_{c}-\min _{s p} w_{c}}\left(w_{c p}^{s}-\max _{s p} w_{c}\right)+u_{c}
$$

These multipliers were applied to the SSP2 persistence assumption values to obtain net migration assumptions for all other SSPs with limits over all periods and scenarios bounded by two standard deviations:

$$
y_{c p}^{s}=m_{c p}^{s} y_{c p}^{S S P 2}
$$

4. A small proportional adjustment to ensure the global sum of $y_{c p}^{s}$ over all countries in each period and scenario sum to zero. Further details of the choice of global adjustment method are given below.

The resulting assumptions, summed to the continental level for each set of SSPs, are shown in the middle column of Figure 1, accompanied by the historic net migration and future assumptions used by the UN in WPP2017.

\section{Scaling to ensure global net migration sums to zero}

In Step 4 of the methodology to link GDP trajectories to net migration, the initial values of $y_{c p}^{s}$ are scaled to ensure that the sum of net migration in each scenario and each period is zero. There are a number of methods to carry out the scaling. One method consists of subtracting the mean net migration flow $\left(\bar{y}_{c p}^{s}\right)$ from $y_{c p}^{s}$,

$$
\hat{y}_{c p}^{s}=y_{c p}^{s}-\bar{y}_{c p}^{s},
$$


to obtain the scaled flows, $\hat{y}_{c p}^{s}$, that sum to zero. This method does not perform well for countries with small net migration values. The shift upwards or downwards from the mean level can result in a country switching from positive net migration to negative net migration (or vice-versa). Further, if the mean net migration value is not close to zero it can create unrealistically large net migration values in small countries. For this reason, an alternative method was used that ensures that countries do not switch from net sending to net receiving countries or vice-versa, whereby weights are calculated and applied separately for positive net migration values $\left(i_{c p}^{s}\right)$ and negative net migration values $\left(e_{c p}^{S}\right)$ :

$$
\hat{y}_{c p}^{s}=\left\{\begin{array}{l}
i_{c p}^{s} a_{c p}^{s} \\
e_{c p}^{s} b_{c p}^{s}
\end{array}\right.
$$

The weights $a_{c p}^{s}=\frac{\sum_{c} i_{c p}^{S}-d_{p}^{S}}{\sum_{c} i_{c p}^{S}}$ scale the positive net migration values, while the weights $b_{c p}^{s}=\frac{\sum_{c} e_{c p}^{S}-d_{p}^{s}}{\sum_{c} e_{c p}^{s}}$ scale the negative values. Both weights are linked by half of the difference in the positive and negative net migration values $d_{p}^{s}=\frac{\sum_{c} i_{c p}^{s}-\sum_{c} i_{c p}^{s}}{2}$ to ensure the scaled flows, $\hat{y}_{c p}^{s}$, sum to zero. 
Abel: Non-zero trajectories for long run net migration assumptions in global population projection models 